\title{
Racial bias: the college, the council, the authors, the journal
}

\author{
Fiona Godlee editor, BMJ
}

Last week we published a study by Aneez Esmail and Chris Roberts addressing the question of whether the exam for entry to the Royal College of General Practitioners may be racially biased (doi:10.1136/bmj.f5662).

The authors found that white UK trained candidates were substantially more likely to pass the clinical skills assessment part of the exam on their first attempt than non-white UK trained candidates and those who trained outside the UK. After adjusting for age, sex, and performance in the college's applied knowledge test, white UK trained candidates were still significantly more likely to pass than were their non-white UK trained colleagues. After additionally adjusting for language skills, the difference between white UK trained and overseas trained candidates disappeared.

The UK's General Medical Council had asked these authors to investigate claims of discrimination using data provided by the college. Their report, published on the same day as their $B M J$ paper (http://bit.ly/GzHlFk), has been interpreted by the college and the GMC as exonerating the exam. But the $B M J$ paper states clearly that subjective bias in the clinical skills assessment cannot be ruled out. "Previous training experience and cultural factors (which include physician-patient relationships, and communication and proficiency in spoken English) could help explain these differences between UK candidates and international medical graduates. However, these cultural factors cannot explain differences between white candidates and black and minority ethnic candidates who have trained in the UK, and who would have had similar training experiences and language proficiency."

The college, which is currently under judicial review after a challenge by the British Association of Physicians of Indian
Origin, has come out fighting. In a letter that is strongly critical of the BMJ's fast track peer review process and of the study's conclusions, college representatives defend the current exam while committing to enhancing the training environment for international medical graduates (doi:10.1136/bmj.f5900). For his part, Aneez Esmail hits back at the college for trying to play down his findings (doi:10.1136/bmj.f5871).

While the various players fight this out, what can readers take away? Both the GMC report and the $B M J$ paper make useful suggestions that, if acted on, could improve perceptions of the exam's fairness, increase the representativeness of UK general practice, and speed up the flow of much needed international medical graduates into the UK. But the stakes are high for all concerned.

There may be some comfort in knowing that the college is not alone in facing this challenge-nor indeed is the UK, as Patrick Dowling makes clear in his editorial (doi:10.1136/bmj.f5765). But neither is this the only challenge facing the college. In a characteristically forthright interview with the $B M J$ this week, departing college chair Clare Gerada reflects on her high profile term in office during one of the NHS's biggest ever reorganisations (doi:10.1136/bmj.f5911). She calls for the internal market to be replaced by an integrated service led by GPs. She also calls for huge investment in primary care, questions the merits of increased regulation, and says that the small business model of general practice has served its time. Her leadership has been widely admired, though not by the incumbent politicians. Hers will be a hard act to follow. 